their care skills to the Hospice at Home team; one has been recruited to a paid role.

Quotes from Care Volunteers:

'I am so proud of myself ....taking on this learning at my age'

'I always dreamed I would be a nurse, now I feel my dream has pretty much come true'

Quote from Staff

'Invaluable'.... 'The support these learners are providing staff and families has already made a massive impact to our services'

Conclusion Comprehensive training can empower volunteers to provide a key role in supporting hands on patient care. Growing our own staff has now become a reality.

\section{P-274 EFFECTIVE VOLUNTEER SUPPORT ON AN INPATIENT UNIT (IPU)}

Rebekah Ashley, Ruth Blunt. Wigan and Leigh Hospice, Greater Manchester, UK

\subsection{6/bmjspcare-2018-hospiceabs.299}

Background We acknowledge the value of volunteers and identified a key part of volunteers feeling appreciated is ensuring they are integrated as part of the team. Review in the line management of volunteers for personable continuity. We explored the volunteer workforce, identifying development areas; shift patterns didn't fully support patients' needs, patients were not benefitting from volunteer interaction, there was crossover between nursing and volunteering duties. Inconsistencies within training and induction.

Aim To develop a beneficial volunteer support on the IPU, delivering specific training, enhancing skills and knowledge, enabling volunteers to safely fulfil their role whilst feeling empowered and valued as part of the wider team.

Method

- Review of duties led to a revised job description

- Established the qualities required to support poorly patients approaching end of life, which formed a person specification

- Recognition of volunteers' commitment and ours in a formal volunteer agreement

- Developing a code of conduct

- Designing specific training and a tailored induction covering relevant policies, procedures and guidelines

- Embedding the hospice values in every communication

- Streamlining duties and shift patterns to avoid duplication

- Updating volunteer contact/next of kin details and shift preferences.

We planned and developed a proposal, held consultation meetings discussing the proposed changes and how they incorporated into practice. This was then followed up with take home reference documents, and then awaited their feedback.

Results The process and improvements have transformed relationships, improved teamwork, empowered volunteers and tailored support for patients, carers and staff, creating cohesive specialist care.

Conclusion Volunteers have a good support network; receive a thorough induction, tailored training and biannual team meetings. Volunteers are more committed - reduced non-attendance. Shift patterns reduced - no duplication of duties. Database of contact details and availability.

\section{P-275 REDUCING BARRIERS TO VOLUNTEERING}

Vanessa Hill, Zoe Byrne. Princess Alice Hospice, Esher, UK

10.1136/bmjspcare-2018-hospiceabs.300

Background A report in 2012 recommended hospices explore new approaches to volunteering to develop skills and widen deployment of volunteers enabling hospices to extend their reach (Help the Hospices, 2012). We recognised the need to broaden the age range of our volunteers, with only $11 \%$ of our volunteers being under 35 years, and the need to develop and expand existing patient facing volunteer roles.

Aims To address barriers to volunteering; offer more flexible volunteer roles; review the areas where volunteers can provide additional support and widen participation.

Methods Survey sent to 950 volunteers; staff consultation and informal feedback from people applying to be volunteers.

Results We identified barriers to volunteering were type of role and rigid role specification. Many want a patient-facing role with flexibility in time commitment. The following initiatives were developed:

- a new, more hands-on ward based volunteer role

- increased range of tasks for teenage ward support volunteers

- volunteer roles attracting those unable to commit to regular days and times

- supporting patients with advance care planning

- discharge buddies supporting patients transitioning to home

- Partnership with a children's centre allowing young mums to commit to training and volunteering.

Our evaluation found for both patients and staff the experience has been positive with more diverse volunteer roles, flexibility in time and initiatives to support those with personal commitments with $7 \%$ more people volunteering in direct patient support. The average age of volunteers has reduced by three years since introducing a more varied volunteer programme.

Conclusions We have enhanced the level of support offered to patients through more hands-on volunteer roles and recognised the need for volunteers to use and develop their skills as well as the need for more flexible opportunities. The ability to provide childcare during volunteer training has enabled people who would traditionally not be available to become volunteers.

\section{P-276 TRANSFORMING VOLUNTEERING}

Minaxi Patel. LOROS Hospice, Leicester, UK

10.1136/bmjspcare-2018-hospiceabs.301

Background Volunteers contribute to patient care directly and indirectly, including the needs of carers, families and friends. There was a need to transform volunteering to make sure volunteering is safe, sustainable and transformational whilst supporting palliative care at the hospice. A new structure was developed to enable:

- Improved communication to and for volunteers

- A direct contact person for volunteers to go to with any concerns

- New processes and procedures to be put into place

- Promote volunteering opportunities for all departments

- Volunteers from all areas to be trained and supported 